\title{
An Analysis of the Environmental Kuznets Curve for Carbon Dioxide Emissions: Evidence for OECD and Non-OECD Countries
}

\author{
Kris Aaron Beck ${ }^{1}$, Prathibha Joshi ${ }^{2}$
}

\begin{abstract}
Over the past two decades, researchers have sought to establish empirical evidence for an Environmental Kuznets Curve (EKC) for carbon dioxide (CO2), with varied results. This study builds on that research to re-evaluate whether the EKC exists for $\mathrm{CO} 2$ emissions, using an improved dataset and the enhanced econometric technique Arellano-Bover/Blundell-Bond Generalized Methods of Moments (GMM) estimator. We directly compare OECD countries with countries of the non-OECD regions of Latin America, Asia, and Africa to determine how various factors like economic growth, population, trade, urbanization, and energy use influence $\mathrm{CO} 2$ emissions. We find that the OECD countries have an N-shaped curve with income growth whereas the regions of Asia and Africa experience an income-based EKC pattern. The results further reveal that population growth has a mixed impact on $\mathrm{CO} 2 \mathrm{emissions,increased} \mathrm{trade} \mathrm{and} \mathrm{urbanization} \mathrm{contribute} \mathrm{to} \mathrm{CO} 2$ emissions for most areas, and increased energy use actually helps to decrease CO2 emissions.
\end{abstract}

Keywords: CO2 • Environmental Kuznets Curve • GMM

JEL Classification Numbers: Q53・Q56・C51

\section{Introduction}

Carbon dioxide $\left(\mathrm{CO}_{2}\right)$ emissions come from the consumption of carbon intensive resources such as wood, coal, or other fossil fuels. The normal planetary carbon cycle usually can regulate these emissions to create a stable feedback system, preventing a dangerous accumulation of $\mathrm{CO}_{2}$ in the atmosphere. However, the vast increase in $\mathrm{CO}_{2}$ emissions from economic development has overwhelmed the ability of the planet to absorb this greenhouse gas (GHG), with emission levels rising 30\% from the $1^{\text {th }}$ century to the late $20^{\text {th }}$ century (Heil and Selden, 2001). Should the $\mathrm{CO}_{2}$ concentration continue to grow, it can radically transform climate patterns to create significant disruptions in the global environment as well as create other environmental problems (Dietz and Rosa, 1997; Shi, 2003). Concerns over these dangers have led researchers to explore more actively the $\mathrm{CO}_{2}$ emissions among countries, particularly by attempting to determine whether or not an Environmental Kuznets Curve (EKC) for $\mathrm{CO}_{2}$ actually exists. Yet previous studies have found mixed results for a $\mathrm{CO}_{2} \mathrm{EKC}$ (Burnett et al., 2013b; Poudel et al., 2009), thereby leading some researchers like Aldy (2005) and Martinez-Zarzoso et al. (2007) to call for additional investigations into the relationship between $\mathrm{CO}_{2}$ emissions and economic growth.

${ }^{1}$ Corresponding Author: Gordon State College, Department of History and Political Science,

419 College Drive, Barnesville, GA, 30204, USA; 678-359-5032;

${ }^{2}$ Gordon State College, Department of Business and Public Service, 419 College Drive,

Barnesville, GA 30204, USA. 
We therefore seek to evaluate how economic growth and other factors impact $\mathrm{CO}_{2}$ emissions with an enhanced dataset from the World Bank Development Indicators 2012and an improved econometric technique of dynamic modeling using the Generalized Method of Moments (GMM) estimator (Arellano and Bover, 1995; Blundell and Bond, 1997). We utilize a panel dataset for OECD countries and the non-OECD regions of Latin America, Asia, and Africa to compare their $\mathrm{CO}_{2}$ emission patterns and determine how economic growth, population growth, increased trade, more urbanization, and higher energy consumption impact $\mathrm{CO}_{2}$ emissions.

The results show that the EKC only appears for the regions of Asia and Africa, with economic development significantly impacting $\mathrm{CO}_{2}$ emissions. However, the OECD countries experience an N-shaped pattern, indicating that additional economic growth may lead people to more readily accept higher $\mathrm{CO}_{2}$ emissions. Population growth has little impact on $\mathrm{CO}_{2}$ emissions for the OECD countries and the Latin American region; yet such growth leads to decreased $\mathrm{CO}_{2}$ emissions for the countries of the Asian region and increased emissions in the high fertility countries of Africa. More trade openness contributes to higher $\mathrm{CO}_{2}$ emissions in the Asian and African regions while greater urbanization promotes higher emissions in all regions except the African region. A rise in energy use also results in decreased $\mathrm{CO}_{2}$ emissions for the OECD countries as well as for the regions of Latin American and Asia, thereby signifying the use of cleaner sources of energy. The rest of the paper proceeds as follows: section 2 offers a selected review of the EKC literature, section 3 reviews the data, section 4 presents the empirical model, section 5 discusses the estimation results, and section 6 offers some conclusions.

\section{Selected Literature Review}

To address the worries by Meadows et al. (1972) over the negative environmental consequences of economic growth, Grossman and Krueger $(1991,1995)$ developed the concept of the Environmental Kuznets Curve. They applied Kuznets (1955) original notion of an inverted $U$ pattern between economic development and income inequality to the relationship between economic development and environmental quality. The EKC theorizes that an inverted $U$ shape also exists for various pollutants where higher income levels tend to foster less environmental degradation. $\mathrm{A} \mathrm{CO}_{2} \mathrm{EKC}$ would see economic development initially contributing to higher emissions but further economic growth then leading to a decrease in those emissions, due to technological advancement and the shift to a service-based economy (Galeotti, 2007).

Yet $\mathrm{CO}_{2}$ has an externality problem that can negatively impact the possibility of an $\mathrm{EKC}$ in that people and countries do not experience direct harms from excessive releases of $\mathrm{CO}_{2}$ (Arrow et al., 1995; Dinda, 2004; Shafik and Bandyopadhyay, 1992). Carbon dioxide does not immediately cause health or environmental problems, as does $\mathrm{SO}_{2}$, nor does emitting $\mathrm{CO}_{2}$ produce strong visible evidence that might inspire public action (Dijkgraaf and Vollebergh, 2005; Halkos, 2003; Lipford and Yandle, 2010; Panayotou, 2003). Instead, $\mathrm{CO}_{2}$ has an indirect but global impact as a GHG (Carson, 2010). Hence people commonly have more of an abstract awareness of the dangers of $\mathrm{CO}_{2}$, which consequently does not often inspire action from them. This $\mathrm{CO}_{2}$ externality can allow $\mathrm{CO}_{2}$ emissions to continue to rise as economic growth expands. 
Nevertheless, some researchers have discovered an $\mathrm{EKC}$ for $\mathrm{CO}_{2}$ in general (Cole et al., 1997; Dietz and Rosa, 1997; Dutt, 2009; Galeotti and Lanza, 1999; Sharma, 2011).Other researchers found a $\mathrm{CO}_{2} \mathrm{EKC}$ only for OECD or high income developed countries (Cole, 2005; Galeotti et al., 2006; Schmalensee et al., 1998). Iwata et al. (2010) discovered an EKC for France but Heil and Selden (2001) foundan EKC only with their levels model. Unruh and Moomaw (1998) argued that the $\mathrm{CO}_{2} \mathrm{EKC}$ merely arose because of the oil shocks of the 1970s. Burnett et al. (2013a) confirmed a weak EKC for the United States but Aldy (2005) found mixed results state by state.

Additional studies, though, failed to find an EKC for $\mathrm{CO}_{2}$ emissions, suggesting that $\mathrm{CO}_{2}$ and other GHGs do not decline after a country reaches a higher stage of economic development. They discovered instead that $\mathrm{CO}_{2}$ emissions increase monotonically with income(Dijkgraaf and Vollebergh, 2005; Galeotti, 2007; Shafik and Bandyopadhyay, 1992; World Bank, 1992). Otherresearchers noticed that $\mathrm{CO}_{2}$ emissions continued to increase only for developing countries (Lipford and Yandle, 2010; Schmalensee et al., 1998).

Moreover, a number of researchers have argued that $\mathrm{CO}_{2} \mathrm{emissions}$ decline only at a very high income per capita (see Cole, 2003), which can prevent countries that lack sufficient resources or development from attaining a decrease in $\mathrm{CO}_{2}$ emissions(Dasgupta et al., 2002). Other research revealed that $\mathrm{CO}_{2}$ emissions occur with an N-shaped curve, with emissions declining after a country reaches high economic development but then increasing again at even higher income levels (Galeotti, 2007;Musolesi and Mazzanti, 2010).

The EKC literature thus has produced many disparate outcomes for $\mathrm{CO}_{2}$ emissions, mostly because the literature resounds with vastly different approaches to evaluating EKCs. For example, researchers have used widely varying time frames in their models. They also have used a variety of assorted datasets and employed distinct econometric methods, making the diverse results inevitable.

\section{Data}

We test for a potential $\mathrm{CO}_{2} \mathrm{EKC}$ by using improved panel datasets created from the World Bank Development Indicators (World Bank, 2012) that have more current data from 1980 to 2008. This study directly compares OECD countries and countries of the non-OECD regions of Latin America, Asia, and Africa. Table 1 defines all of the variables used in the study and provides summary statistics for the OECD countries and the three regions. It also presents the mean and standard deviations for each variable.

TABle 1: Definition of VARIables \& Summary STATistics FOR OECD \& NON-OECD REGION COUNTRIES

Variable Description of the Variables $\quad$ Mean Std.Dev. Obs.

\section{OECD}

$\mathrm{CO} 2$ 


$\begin{array}{lllll}\text { PCI } & \text { GDP per capita (constant 2000 US\$) } & 21407.28 & 9226.42 & 628 \\ \text { POPG } & \text { Population growth (annual \%) } & 0.59 & 0.46 & 638 \\ \text { TOT } & \text { Net barter terms of trade index }(2000=100) & 100.97 & 11.78 & 218 \\ \text { URBAN } & \text { Urban population (\% of total) } & 73.47 & 11.72 & 638 \\ \text { ENGY } & \text { Energy use (kg of oil equivalent per capita) } & 4362.59 & 1847.80 & 638\end{array}$

\section{Non- OECD Regions}

\section{Latin.Am.}

$\begin{array}{lllll}\text { CO2 } & \text { CO2 emissions (metric tons per capita) } & 2.65 & 3.86 & 638 \\ \text { PCI } & \text { GDP per capita (constant 2000 US\$) } & 3136.80 & 2009.78 & 627 \\ \text { POPG } & \text { Population growth (annual \%) } & 1.68 & 0.71 & 638 \\ \text { TOT } & \text { Net barter terms of trade index (2000 = 100) } & 110.04 & 34.35 & 587 \\ \text { URBAN } & \text { Urban population (\% of total) } & 60.51 & 19.57 & 638 \\ \text { ENGY } & \text { Energy use (kg of oil equivalent per capita) } & 1164.79 & 1542.84 & 638 \\ \text { Asia } & & & & \\ \text { CO2 } & \text { CO2 emissions (metric tons per capita) } & 2.97 & 3.93 & 319 \\ \text { PCI } & \text { GDP per capita (constant 2000 US\$) } & 3309.58 & 6016.36 & 319 \\ \text { POPG } & \text { Population growth (annual \%) } & 1.81 & 0.85 & 319 \\ \text { TOT } & \text { Net barter terms of trade index (2000 =100) } & 104.54 & 20.38 & 296 \\ \text { URBAN } & \text { Urban population (\% of total) } & 39.31 & 26.10 & 319 \\ \text { ENGY } & \text { Energy use (kg of oil equivalent per capita) } & 1130.44 & 1299.28 & 319 \\ \boldsymbol{A f r i c a} & & & & \\ \text { CO2 } & \text { CO2 emissions (metric tons per capita) } & 1.43 & 2.67 & 348 \\ \text { PCI } & \text { GDP per capita (constant 2000 US\$) } & 994.57 & 1336.99 & 348 \\ \text { POPG } & \text { Population growth (annual \%) } & 2.62 & 0.69 & 348 \\ \text { TOT } & \text { Net barter terms of trade index (2000 = 100) } & 120.57 & 45.98 & 348 \\ \text { URB } A N & \text { Urban population (\% of total) } & 41.13 & 12.68 & 348 \\ \text { ENGY } & \text { Energy use (kg of oil equivalent per capita) } & 744.87 & 689.76 & 348\end{array}$

Notes: The source of the database is World Development Indicators 2012. The time period is from 1980 to 2008 .

The $\mathrm{CO}_{2}$ emission rate is the dependent variable, $\mathrm{CO} 2$, measured in terms of metric tons per capita ${ }^{1}$. These emissions come from the use of fossil fuels in production and consumption as well as cement manufacturing (World Bank, 2012). The independent variables of the model include the lagged dependent variable, GDP, population growth, trade, urbanization, and energy use. We use $C O_{2 t-1}$ with the idea that the externality of

${ }_{1}$ The World Bank uses data for $\mathrm{CO}_{2}$ from the Carbon Dioxide Information and Analysis Center (CDIAC) located at the Oak Ridge National Laboratory for $\mathrm{CO}_{2}$. 
$\mathrm{CO}_{2}$ suggests that countries with high $\mathrm{CO}_{2}$ emissions generally will persist in generating elevated emissions over time, particularly considering the difficulties and costs of reducing $\mathrm{CO}_{2}$ at the source of emissions (Martinez-Zarzoso et al., 2007). PCI denotes per capita GDP and we include the quadratic form, $P C I^{2}$, to determine if it confirms the EKC. Although other studies have used GDP Purchasing Power Parity, the World Bank Development Indicators have some missing data that makes using PPP impractical; hence we utilize GDP per capita in terms of 2000 US\$.

Population growth, POPG, is a common variable of interest in the EKC literature. Some studies have found that an increasing population has little influence on $\mathrm{CO}_{2}$ emissions (Dutt, 2009); other research, though, has demonstrated that population growth directly increases $\mathrm{CO}_{2}$ pollution levels (Dinda, 2004; Martínez-Zarzosa et al., 2007; Shi, 2003). We use overall population growth specifically to determine how it might affect per capita emissions; an increase in $\mathrm{CO}_{2}$ emissions per person due to a rise in total population would indicate an additive effect, where every additional person actually increases each person's per capita emissions. However, a decrease in per capita $\mathrm{CO}_{2}$ emissions following an increase in overall population would denote a subtractive effect, where additional population numbers lead to fewer emissions per person.

The independent variable TOT, the net barter terms of trade index, measures trade openness. The literature has produced different results for trade openness, with some research suggesting that more trade can allow for the importation of energy efficient devices that reduce $\mathrm{CO}_{2}$ emissions but other studies arguing that additional trade creates added pollution for developing countries especially (Sharma, 2011). While we test for these consequences of trade, the World Bank data does have missing data for some countries that makes measuring trade's impact more difficult. The variable for urbanization, $U R B A N$, is assessed by looking at the urban population of the countries as a percentage of the total population. Most research has demonstrated that greater urbanization leads to more air pollution (Cole and Neumayer, 2004; Sharma, 2011).

Energy use, ENGY, reflects "the use of primary energy before transformation to other end-use fuels" (World Bank, 2012). One major argument asserts that increasing energy use naturally leads to higher $\mathrm{CO}_{2}$ emissions, especially with energy coming from fossil fuels (Sharma, 2011). Yet other research has allowed for the influence of non-polluting alternative sources of energy that can reduce emissions (Iwata et al., 2010), even as the shift to a service economy often results in less energy use by a country (Shi, 2003). Following Atici (2009), we therefore make energy use a proxy for technological development, with the expectation that a positive sign denotes dependence on more heavily polluting energy technologies but a negative sign indicates the adoption of cleaner technologies.

The early literature on Environmental Kuznets Curves additionally often sought to establish a universal turning point for all countries (Grossman and Krueger, 1991). Later work argued strenuously against such "income determinism" (Unruh and Moomaw, 1998),suggesting that development trajectories can be similar or dissimilar but rarely exact (Cole, 2005; Galeotti and Lanza, 1999; Webber and Allen, 2010). Likewise, we argue that $\mathrm{CO}_{2}$ turning points at best only represent the average among all the countries rather than a deterministic summit that marks the start of the downward phase of the curve; therefore we do not ascertain turning points. 


\section{Empirical Model}

Many researchers throughout the EKC literature have relied on fixed or random effects linear models to produce their econometric results. However, these estimation methods have significant problems like heteroskedasticity and importantly endogeniety(Cole, 2003; Lee et al.2003), which then limits their effectiveness in determining the actual relationships among $\mathrm{CO}_{2}$ emissions, economic development, and other factors. Halkos (2003) suggested that these previous methods thus had considerable problems with misspecification and could not accurately depict EKC patterns.

Other researchers, though, have recognized that the complex interaction over time between economic growth and $\mathrm{CO}_{2}$ itself is dynamic rather than linear (Carson, 2010; Dinda, 2004). Various studies consequently have adopted non-linear dynamic modeling with the understanding that it better accounts for the changing aspects of the data and can produce more efficient results by controlling for time-based autocorrelation (Auffhammer and Carson, 2008; Burnett et al., 2013a). In particular, some researchers have used Generalized Method of Moments (GMM) to achieve their estimation results because it offers an instrumental variable estimation technique that attains consistency and accuracy (Halkos, 2003; Lee et al., 2003). As a dynamic model, GMM has particular relevance for solving country-specific effects and endogeneity.

The GMM model uses first differences in the equation to control for unobserved country-specific effects like geographic features, daily climatic change, etc. (Maddison, 2006; Sharma, 2011).We also recognize potential endogeneity concerns with the energy use regressor; we therefore instrument this variable by using a one period lag. The GMM estimation consequently reduces the error term to "white noise," thereby eliminating endogeneity due to correlation between the error term and the independent variables (Halkos, 2003). The lag of the energy use variable also prevents endogeneity due tosimultaneity bias (Lee et al. 2010), particularly in that current emissions of $\mathrm{CO}_{2}$ cannot influence past levels of energy use. In eliminating endogeneity, we restore the orthogonality conditions of the independent variables to attain "unbiased and consistent estimates" (Halkos, 2003). The GMM estimation thus works under the assumption that all independent variables besides the lagged dependent variable are exogenous and act as valid instruments. The GMM estimation technique therefore corrects for heteroskedasticity and it creates efficient as well as unbiased results. ${ }^{2}$

The equation for the model takes a modified form of the Arellano-Bover/BlundellBond $(1995,1998)$ GMM dynamic panel-data estimation that corrects the bias problems that occurred with earlier forms of GMM. In particular, it employs additional moment conditions and places "further restrictions on the initial conditions process" (Blundell and Bond, 1998, 116) to gain more flexibility for smaller time observations. The equation uses balanced panel data and is specified in an expanded logarithmic form as follows for both the OECD countries and the non-OECD regions:

${ }^{2}$ For a more detailed explanation, see Arellano and Bond (1991), Arellano and Bover (1998),Blundell and Bond (1997), and Halkos (2003). 
$\Delta \operatorname{lnCO} 2_{\text {it }}=\beta_{1} \Delta \ln \left(\mathrm{CO} 2_{\mathrm{i}, \mathrm{t}-1}\right)+\beta_{2} \Delta \ln \left(\mathrm{PCI}_{\mathrm{it}}\right)+\beta_{3} \Delta \ln \left(\mathrm{PCI}_{\mathrm{it}}\right)^{2}+\beta_{4} \Delta \ln \mathrm{POPGit}+\beta_{5} \Delta \ln \mathrm{TOT}_{\mathrm{it}}$ $+\beta_{6} \Delta \ln \mathrm{URBAN}_{\mathrm{it}}+\beta_{7} \Delta \ln \mathrm{lnNGY} \mathrm{i}_{\mathrm{i}-\mathrm{1}-1}+\Delta \varepsilon_{\mathrm{it}}$

where $\mathrm{CO} 2$ is carbon dioxide emissions; $\left(\mathrm{CO} 2_{t-1)}\right.$ represents the lagged dependent variable; $P C I$ denotes per capita GDP, $P C I^{2}$ signifies the quadratic form of GDP per capita, $P O P G$ is population growth, TOT represents trade, URBAN signifies urbanization, ENGY denotes energy use, $\varepsilon_{i t}$ is the standard error term; subscript i equals the country, and subscript $t$ represents the time period. The model engages the autocorrelation $A R(1)$ and $\mathrm{AR}(2)$ tests to examine for evidence of serial correlation of the error term.

\section{Estimation Results}

Table 2depicts the outcomes of the GMM estimation for the dependent variable CO2. It also shows the $z$-values for each variable. The economic and statistical significance of the independent variables display both positive and negative aspects. For the OECD countries and all three non-OECD regions, the test for no autocorrelation in the differenced error term $\mathrm{AR}(1)$ is significant and rejects the null hypothesis of no serial correlation; however the second-order test $\mathrm{AR}(2)$ cannot reject the null hypothesis, following standard expectations for the GMM model and suggesting that autocorrelation does not exist.

TABle 2: GMM Estimation Results (DEPENDENT VAR. LOG OF CO2)

\begin{tabular}{|c|c|c|c|c|c|c|c|}
\hline Variables & $\begin{array}{l}\text { Model } \\
1 \\
\text { OECD }\end{array}$ & & $\begin{array}{l}\text { Model } \\
2 \\
\text { Latin. } A \\
m .\end{array}$ & & $\begin{array}{l}\text { Model } \\
3 \\
\text { Asia }\end{array}$ & & $\begin{array}{l}\text { Model } \\
4 \\
\text { Africa }\end{array}$ \\
\hline \multirow[t]{2}{*}{ CO2(L1) } & 0.849 & $\begin{array}{l}* * \\
*\end{array}$ & 0.779 & $\begin{array}{l}* * \\
*\end{array}$ & 0.885 & $\begin{array}{l}* * \\
*\end{array}$ & 0.746 \\
\hline & $(0.027)$ & & $(0.027)$ & & $(0.023)$ & & (0.035) \\
\hline \multirow[t]{2}{*}{$P C I$} & -1.032 & $* *$ & -0.214 & & 0.106 & & 1.148 \\
\hline & $(0.513)$ & & $(0.259)$ & & $(0.074)$ & & $(0.297)$ \\
\hline \multirow[t]{2}{*}{$\mathrm{PCI}^{2}$} & 0.046 & $* *$ & 0.012 & & -0.007 & * & -0.087 \\
\hline & $(0.024)$ & & $(0.017)$ & & $(0.004)$ & & $(0.022)$ \\
\hline \multirow[t]{2}{*}{ POPG } & 0.004 & & 0.011 & & -0.023 & $* *$ & 0.082 \\
\hline & $(0.003)$ & & $(0.015)$ & & $(0.012)$ & & $(0.039)$ \\
\hline \multirow[t]{2}{*}{ TOT } & 0.027 & & 0.034 & & 0.049 & $* *$ & 0.107 \\
\hline & $(0.024)$ & & $(0.023)$ & & $(0.025)$ & & (0.048) \\
\hline \multirow[t]{2}{*}{$U R B A N$} & 0.089 & * & 0.137 & $* *$ & 0.129 & $* *$ & 0.093 \\
\hline & (0.054) & & (0.038) & & $(0.048)$ & & (0.102) \\
\hline \multirow[t]{2}{*}{ ENGY(L1) } & -1.253 & $* *$ & -0.611 & ** & -0.818 & ** & -0.244 \\
\hline & $(0.075)$ & & (0.088) & & $(0.073)$ & & $(0.272)$ \\
\hline
\end{tabular}




\begin{tabular}{|c|c|c|c|c|c|c|c|c|c|}
\hline Constant & & & $\begin{array}{l}3.668 \\
(2.382)\end{array}$ & & $\begin{array}{l}-1.867 \\
(1.168)\end{array}$ & & $\begin{array}{l}-1.539 \\
(0.426)\end{array}$ & $\begin{array}{l}* * \\
*\end{array}$ & $\begin{array}{l}-7.864 \\
(1.371)\end{array}$ \\
\hline Number of Observations & & & 207 & & 556 & & 285 & & 331 \\
\hline Number of Countries & & & 22 & & 22 & & 11 & & 12 \\
\hline Wald chi2 test & & & $\begin{array}{l}19213 . \\
6\end{array}$ & $\begin{array}{l}* * \\
*\end{array}$ & 8128.18 & $\begin{array}{l}* * \\
*\end{array}$ & $\begin{array}{l}38342 . \\
09\end{array}$ & $\begin{array}{l}* * \\
*\end{array}$ & $\begin{array}{l}2265.0 \\
3\end{array}$ \\
\hline $\begin{array}{l}\text { Arellano-Bond Test } \\
\text { autocorrelation } \mathrm{AR}(1)\end{array}$ & for & zero & -2.77 & $\begin{array}{l}* * \\
*\end{array}$ & -2.78 & $\begin{array}{l}* * \\
*\end{array}$ & -2.50 & $* *$ & -2.38 \\
\hline Arellano-Bond Test & for & zero & -0.75 & & 0.35 & & 0.98 & & -0.81 \\
\hline
\end{tabular}
autocorrelation $\operatorname{AR}(2)$

Notes: Parentheses marks standard errors. Significance at $10 \%$ shown by $*$; at $5 \%$ by **; and at $1 \%$ by ***. L1 stands for lag of one period.

OECD countries: Australia, Austria, Belgium, Canada, Denmark, Finland, France, Greece, Ireland, Italy, Japan, Luxembourg, Netherlands, New Zealand, Norway, Poland, Portugal, Spain, Sweden, Switzerland, United Kingdom, United States

Latin America: Argentina, Bolivia, Brazil, Chile, Colombia, Costa Rica, Cuba, Dominican Republic, Ecuador, El Salvador, Guatemala, Haiti, Honduras, Jamaica, Mexico, Nicaragua, Panama, Paraguay, Peru, Trinidad and Tobago, Uruguay, Venezuela, $R B$

Asia: Bangladesh, China, India, Indonesia, Korea, Rep., Malaysia, Nepal, Pakistan, Singapore, Sri Lanka, Thailand

Africa: Benin, Cameroon, Congo, Dem. Rep., Cote d'Ivoire, Gabon, Ghana, Nigeria, Senegal, South Africa, Sudan, Zambia, Zimbabwe

In examining 22 OECD countries, we find that the lagged dependent variable CO2(L1) is positive and statistically significant at the $1 \%$ level, signifying that high $\mathrm{CO}_{2}$ emissions do occur continuously from the past to the future.

$P C I$ is negative and significant but the quadratic variable $P C I^{2}$ is positive and statistically significant at the $5 \%$ level, suggesting an $\mathrm{N}$-shaped pattern where previously rising $\mathrm{CO}_{2}$ emissions start to decline at high income levels only to rise again as that per capita income continues to grow. The results therefore do not confirm an EKC for the OECD countries as a whole, although such an outcome does not mean that countries can not have individual EKCs, such as in France (Iwata et al.,2010). Hence these outcomes counter the findings of an EKC for $\mathrm{CO}_{2}$ in such studies as Cole (2005), Galeotti et al. (2006), and Schmalensee et al. (1998) but verify Galeotti (2007) as well as Musolesi and Mazzanti (2010). The implication is that people and governments become more willing to accept higherCO $\mathrm{C}_{2}$ emissions at very high income levels particularly because they desire an elevated standard of living or they want to emphasize continual economic growth above the environment, as seen by the refusal of the United States to sign the Kyoto Accord. Consequently, an enhanced scale effect appears where $\mathrm{CO}_{2}$ emissions once again are linked to economic growth (Dinda, 2004), thereby countering previous gains in $\mathrm{CO}_{2}$ reductions.

$P O P G$, though, lacks significance as a variable, suggesting that population growth has little impact on $\mathrm{CO}_{2}$ emissions for OECD countries. Such results corroborate Dutt (2009) but contradict earlier studies on population and $\mathrm{CO}_{2}$ (Dietz and Rosa, 1997; Shi, 2003). Trade openness, TOT, shows a positive sign but also is insignificant. This outcome denotes that increases in trade have little impact onCO $\mathrm{C}_{2}$ emissions, possibly because the OECD countries have better and cleaner technologies for production and abatement. 
$U R B A N$ has a positive and significant sign, thereby verifying previous studies that linked higher urbanization with more $\mathrm{CO}_{2}$ pollution (Cole and Neumayer, 2004; Sharma, 2011). As a country urbanizes, cities grow larger by massing both people and industry into these central areas. The cities thus require more resources but also concentrate emissions through that industry. In addition, cities tend to foster more of a $\mathrm{CO}_{2}$ producing car culture, even when public transportation is available, so that people can escape the central core of the city and live in the suburbs.

A negative and significant result emerges for energy use, ENGY, which suggests the reliance on less polluting technologies. This outcome indicates that increased energy use leads to decreased $\mathrm{CO}_{2}$ emissions, perhaps because OECD countries tend to have the technology to clean emissions from $\mathrm{CO}_{2}$ producing power plants and have experimented more with alternative sources of energy like nuclear, hydroelectric, wind, solar, etc. (Martínez-Zarzosa et al.,2007).

The three regions of the non-OECD countries show different results for some variables but more often than not share similar outcomes, suggesting that these variables do have a strong impact on $\mathrm{CO}_{2}$ emissions overall. For each region, the lagged dependent variable C02(L1)showed positive and significant results at the 1\% level, again signifying that high $\mathrm{CO}_{2}$ emission levels continue from year to year possibly due to the difficulty and costs of treating emissions.

The economic impact results confirm an EKC pattern only for the non-OECD regions of Asia and Africa, with $P C I$ as positive and significant and $P C I^{2}$ negative and significant for the African region and $P C I$ as positive and insignificant but $P C I^{2}$ negative and significant for the Asia region. These outcomes imply that the countries of Asia and Africa have reached the stage where they can start to reduce their $\mathrm{CO}_{2}$ emissions as they grow economically. Hence such results confirm previous efforts that found that a $\mathrm{CO}_{2}$ EKC can occur in countries as they develop economically (Cole et al., 1997; Dietz and Rosa, 1997; Dutt, 2009; Galeotti and Lanza, 1999; Sharma, 2011). Nevertheless, the Latin American region showed insignificant outcomes for both $P C I$ and $P C I^{2}$, thereby implying that an EKC does not exist.

The POPG variable shows that population growth is positive and significant only for the African region, thereby partially confirming Martínez-Zarzosa et al. (2007) and Shi (2003). Population growth thus substantially impacts per capita $\mathrm{CO}_{2}$ emissions particularly for the countries of sub-Saharan Africa that are experiencing very rapid and considerable population growth. The POPG variable turned out insignificant and positive for the Latin American region but significant and negative for the Asian region. The results for the Latin American region verify Dutt (2009); the outcomes for the Asian region, though, seem counter-intuitive since a population increase generally means that greater numbers of people place ever escalating demands on available resources, leading to an accelerated depletion of those resources as well as the creation of larger amounts of waste (Dietz and Rosa, 1997). Nevertheless, an argument can be made that many nonOECD countries have as yet to develop a high enough standard of living to allow their population to truly impact $\mathrm{CO}_{2}$ emissions; these countries have such limited economic development that increased production and consumption from population growth have relatively small impacts on emissions. 
The results for the trade openness variable, TOT, are positive and significant for the countries of the Asian and African regions but insignificant for those of the Latin American region. Overall, then, these outcomes imply that $\mathrm{CO}_{2}$ emissions rise as trade with other countries occurs more often. Part of this outcome comes from the scale effect, which suggests that these countries have enlarged the scope of their industrial base to meet enlarged trade demands (Dinda, 2004). Increased trade also raises the specter of the Pollution Haven Hypothesis where more polluting industries go to developing countries to escape the regulations on their operations found in developed countries as well as to exploit cheap labor (Carson, 2010; Cole, 2004; Panayotou, 2003). As other studies have recognized, this scenario presents some difficulties for the developing countries since it worsens their environment, which then can negatively impact further economic growth.

The outcomes for urbanization, $U R B A N$, for Latin American and Asia show significant and positive signs, generally verifying previous studies that show that as a country urbanizes the amount of $\mathrm{CO}_{2}$ it emits escalates dramatically. As with developed countries, many developing countries have begun to embrace more of a car culture that leads to considerable $\mathrm{CO}_{2}$ emissions, even as these developing countries dedicate more of their resources to the cities; in doing so, they produce more waste products like $\mathrm{CO}_{2}$ as well.

Energy use, ENGY, has a negative and significant result for the regions of Latin America and Asia, where increased energy use actually lowers $\mathrm{CO}_{2}$ emissions. These outcomes thus denote that these regions have begun to adopt newer, cleaner technologies to produce energy. The results for the African region are negative but insignificant, suggesting that energy use has little impact on $\mathrm{CO}_{2}$ emissions for the countries of these regions. Hence these results signify that economic growth can motivate a rising use of better energy technology that reduce emissions, often through the trade in technological advancements (Cole, 2003).

An overall comparison does confirm that the $\mathrm{CO}_{2}$ emission paths differ among the OECD countries and those of the three non-OECD regions, as expected since they are in different stages of economic growth. In addition, the three regions do diverge in terms of how some variables impact their $\mathrm{CO}_{2}$ emissions. Essentially, the GMM estimation results show that the OECD countries have gone beyond the basic EKC pattern whereas the Asian and African regions have begun to directly experience it, although the OECD results do suggest that these two regions might themselves eventually transcend the EKC to an $\mathrm{N}$-shaped pattern as well. However, the N-shaped curve does not necessarily invalidate the dynamics of an EKC, where $\mathrm{CO}_{2}$ emissions initially rise but do eventually level off and then decline as economic development and other factors impact the emissions levels. The EKC does emerge, if only partially and temporarily.

\section{Conclusion}

Since all countries approach economic development and environmental regulation differently, many studies have produced a wide variety of results that tend to conflict with each other. While some agree that an EKC will exist for $\mathrm{CO}_{2}$ emissions, other studies question whether the $\mathrm{CO}_{2}$ EKC actually exists or if it is an artificial 
construct of econometrics. We therefore have re-examined the relationship between $\mathrm{CO}_{2}$ emissions, economic development, population, trade openness, urbanization, and energy use to further discover any patterns that might provide more insight into these relationships, using a more current and extensive dataset from the World Bank as well as the better econometric dynamic model of Arellano-Bover/Blundell-Bond GMM estimation.

We discover that an EKC based on economic growth only exists for the non-OECD regions of Asia and Africa, while the region of Latin America shows no evidence for it at all and the OECD countries have bypassed it into the $\mathrm{N}$-shaped pattern. Any reductions in $\mathrm{CO}_{2}$ emissions, though, can benefit the planet even without similar reductions by other countries or regions; the overall $\mathrm{CO}_{2}$ concentrations will not increase as much or as rapidly as might occur with all of these countries emitting high levels of $\mathrm{CO}_{2}$. Yet the non-OECD countries risk a transition into the $\mathrm{N}$-shaped curve when the externality of $\mathrm{CO}_{2}$ and their own desire to develop the high standard of living of the OECD countries weaken their willingness to take action. The results also show that population has some influence on $\mathrm{CO}_{2}$ emissions overall, trade openness and urbanization tends to increase $\mathrm{CO}_{2}$ discharges, and expanded energy use often leads to decreased emissions for most of the countries in the study.

The worry is that continued $\mathrm{CO}_{2}$ emissions can overwhelm the carrying capacity of the planet, leading to irreversible and adverse climate change throughout the world. Galeotti (2007) as well as Webber and Allen (2010) have argued that economic development can create immense negative environmental impacts before countries reach the downward phase of the EKC pattern. The suggestion is that the damage already done might necessitate reducing further $\mathrm{CO}_{2}$ emissions in both developed and developing countries so that the environment can recover or stabilize and economies do not become further threatened by additional degradation. Accordingly, we present some important general implications for policy development that can apply to all countries.

First, both developed and developing countries should devote more resources to creating efficient and cheap mass transportation as well as better infrastructure; such investments can counter the increasing $\mathrm{CO}_{2}$ emissions coming from existing and newly emerging car cultures, particularly in India and China. Second, developed countries should take the initiative to engage in technology and knowledge transfers to developing countries, allowing the developing countries to flatten their curve before they create irreversible damage to the planet. This support also can include financial assistance to help the developing countries pay for abatement and the installation of better technologies.

Third, countries across the world regardless of their development status should educate their citizens more fully about the dangers of excessive $\mathrm{CO}_{2}$ concentrations and mass overconsumption of resources. Nongovernmental organizations also can help in this education process. These countries and organizations then should seek to foster in people a stronger willingness to solve these problems. In these ways, $\mathrm{CO}_{2}$ concentrations eventually can decrease and the world can avert an environmental catastrophe. 


\section{References}

Aldy, J. (2005).An Environmental Kuznets Curve Analysis of U.S. State-Level Carbon Dioxide Emissions. The Journal of Environment Development, 14, 48-72.

Arellano, M.,\&Bond,S.(1991).Some tests of specification for panel data: Monte Carlo evidence and an application to employment equations. The Review of Economic Studies, 58, 277-297. Arellano, M.,\&Bover,O.(1995). Another look at the instrumental variable estimation of errorcomponents models.Journal of Econometrics, 68, 29-51.

Arrow, K., Bolin,B., Costanza,R., Dasgupta, P., Folke,C., Holling, C.S., Jansson,B., Levin,S.,

Mäler,K., Perrings, C.,\&Pimental, D.(1995). Economic growth, carrying capacity, and the environment.Science, 268, 520-521.

Atici, C. (2009).Carbon emissions in Central and Eastern Europe: Environmental Kuznets curve and implications for sustainable development. Sustainable Development, 17, 155-160.

Auffhammer, M., Steinhauser, R. (2007). The future trajectory of US CO2 emissions: the role of state vs aggregate information. Journal of Regional Science, 47(1), 47-61.

Blundell, R.,\&Bond, S. (1998).Initial conditions and moment restrictions in dynamic panel data models. Journal of Econometrics,87:115-143.

Burnett, J.W., Bergstrom, J.C., and Wetzstein, M.E. (2013a). Carbon dioxide emissions and economic growth in the U.S. Journal of Policy Modeling, 35, 1014-1028.

Burnett, J.W., Bergstrom, J.C., and Dorfman, J.H. (2013b). A spatial pane data approach to estimating U.S. state-level energy emissions. Energy Economics, 40, 396-404.

Carson, R.T. (2010). The environmental Kuznets curve: seeking empirical regularity and theoretical structure. Review of Environmental Economics and Policy, 4(1), 3-23.

Cole, M.A. (2003). Development, trade, and the environment: how robust is the environmental Kuznets curve? Environment and Development Economics, 8, 557-580.

Cole, M.A. (2005). Re-examining the pollution-income relationship: a randomcoefficients approach.Economics Bulletin,14(1), 1-7.

Cole, M.A., Rayner,A., \&Bates, J. (1997). The environmental Kuznets curve: an empirical analysis.Environment and Development Economics, 2(4), 401-416.

Cole, M.A., \&Neumayer, E. (2004). Examining the impact of demographic factors on air pollution. Population and Environment,26(1), 5-21.

Dasgupta, S., Laplante,B., Wang,H., \&Wheeler, D. (2002). Confronting the environmental Kuznets curve. The Journal of Economic Perspectives, 16(1), 147-168.

Dietz, T.,\&Rosa, E. (1997). Effects of population and affluence on $\mathrm{CO}_{2}$ emissions. Proceedings of the NationalAcademyof Sciences USA,94, 175-179.

Dijkgraaf, E.,\&Vollebergh, H. (2005). A test for parameterhomogeneity in $\mathrm{CO}_{2}$ panel EKC estimations.Environmental and Resource Economics,32, 229-239.

Dinda, S. (2004). Environmental Kuznets curve hypothesis: asurvey.Ecological Economics, 49(4), 431-455.

Dutt, K. (2009).Governance, institutions and the environment-income relationship: a crosscountry study.Environment, Development and Sustainability, 11, 705-723.

Galeotti, M. (2007).Economic growth and the quality of the environment: taking stock. Environment, Development and Sustainability, 9, 427-454.

Galeotti, M.,\&Lanza, A. (1999).Richer and cleaner? A study on carbon dioxide emissions in developing countries.Energy Policy,27(10), 565-573.

Galeotti, M., Lanza,A., \&Pauli, F. (2006).Reassessing the environmental Kuznets curve for $\mathrm{CO}_{2}$ emissions: a robustness exercise.Ecological Economics, 57, 152-163.

Grossman, G.M.,\&Krueger, A. (1991).Environmental impacts of a North American free trade

agreement. Working Paper 3914, NBER. Also published in 1993 in P.M. Garber(Ed.) The Mexico-US free trade agreement(pp. 13-57). Cambridge, MA: The MIT Press.

Grossman, G.M.,\&Krueger, A. (1995).Economic growth and the environment.The Quarterly Journalof Economics, 110(2), 353-377.

Halkos, G. (2003). Environmental Kuznets curve for sulfur: evidence using GMM estimation and random coefficients panel data models. Environment and Development Economics, 8, 581-601.

Heil, M.,\&Selden, T. (2001).Carbon emissions and economic development: future trajectories 
based on historical experience.Environment and Development Economics, 6, 63-83.

Iwata, H., Okada,K., \&Samreth, S. (2010).Empirical study on the environmental Kuznets curve for $\mathrm{CO}_{2}$ in France: the role of nuclear energy.Energy Policy,38(8), 4057-4063.

Kuznets, S. (1955).Economic growth and income inequality. The American EconomicReview, 45(1), 1-28.

Lipford, J.\&Yandle, B. (2010).Environmental Kuznets curves, carbon emissions, and public choice.Environment and Development Economics, 15, 417-438.

Maddison, D. (2006). Environmental Kuznets curves: a spatial econometric approach, Journal of Environmental Economics and Management, 51(2), 218-230.

Martínez-Zarzosa, I., Bengochea-Morancho,A., \&Moreales-Lage, R. (2007).The impact of

population on $\mathrm{CO}_{2}$ emissions: evidence from European countries.Environmental and Resource Economics,38, 497-512.

Meadows, D.H., Meadows,D.L., Randers,J., \&Behrens, W.W. (1972). The limits to growth . London: Earth Island Limited.

Musolesi, A.,\&Mazzanti, M. (2010). Apanel dataheterogeneous Bayesian estimation of environmental Kuznets curves for $\mathrm{CO}_{2}$ emissions. Applied Economics,42(18), 2275-2287.

Panayotou, T. (2003).Economic growth and the environment.Economic Survey of Europe,2, 45-72.

Poudel, N., Paudel, K. \& Bhattarai, K. (2009). Searching for an environmental Kuznets curve in carbon dioxide pollutant in Latin American countries. Journal of Agricultural and AppliedEconomics, 41(1), 13-27.

Schmalensee, R., Stoker,T., \&Judson, R. (1998).World carbon dioxide emissions: 1950-2050. The Review of Economics and Statistics, 80(1), 15-27.

Shafik, N.,\&Bandyopadhyay, S. (1992).Economic growth and environmental quality: timeseries and cross-country evidence.Working Paper 904, Washington, D.C., The World Bank. Sharma, S. (2011).Determinants of carbon dioxide emissions: empirical evidence from 69 countries. Applied Energy,88, 376-382.

Shi, A. (2003).The impact of population pressure on global carbon dioxide emissions, $1975-$ 1996: evidence from pooled cross-country data. Ecological Economics, 44, 29-42.

Unruh, G.C.,\&Moomaw, W.R. (1998).An alternative analysis of apparent EKC-type transitions. Ecological Economics, 25, 221-229.

Webber, D.,\&Allen, D. (2010).Environmental Kuznets curves: mess or meaning?International Journal of Sustainable Development and World Ecology,17(3), 198-207.

World Bank (1992). World Bank development report 1992: development and the environment. World Bank, Washington, D.C.

World Bank (2012). World Bank development indicators. World Bank, Washington D.C. 